\title{
Exposure to vehicle exhaust causes decline in lung
} functions

\begin{abstract}
Introduction: Air pollution from vehicles is an inevitable part of the workers at gasoline stations. A long-term exposure to such air pollution of vehicles exhaust would leads to damaging effects on general health and the pulmonary function in particular. A number of studies have found an increased prevalence of respiratory symptoms in populations live near roadways with high traffic counts.
\end{abstract}

Aims and objectives: The present study was aimed to investigate the extent of pulmonary function changes due to exposure to exhaust vehicles on car maintenance workers at gas stations in Eastern Province, Saudi Arabia. Furthermore, we also assessed the relationship between the duration of the service at the gas stations with pulmonary function decline.

Materials and methods: Twenty males aged from 18-40years whom working in gas stations as a cars mechanics were recruited in this study. Studied subjects were categorized into two groups, depending on the duration of the exposure [first group $>5$-years; second group $<5$ years]. Pulmonary function parameters were measured as FEV1, FVC and FEV\%, using portable spirometry during their working hours. For air pollution, MIRAN SapphIRe Portable Ambiant Analyzer, GrayWolf and Aerosol and Dust Monitors were used and its value was compared with World Health Organization (WHO) and Saudi standards.

Results: Shortness of breath, dizziness and chest pain were the most prevalent symptoms among workers. Workers with less than 5 years showed symptoms as follow: $10 \%, 30 \%$ and $25 \%$; while the workers with more than 5years: $30 \%, 35 \%$ and $30 \%$. FVC (L) and FEV1 (L) data showed significant decrease compared to the control group [ANOVA p=0.006; ANOVA p=0.007], while FEV1\% (FEV1/FVC) value showed significant increase compared to the control group [ANOVA $p=0.001$ ]. Air pollution data showed a significant increase in dust, $\mathrm{NO}_{2}$, VOC and $\mathrm{SO}_{2}$ comparing with WHO and Saudi Standards.

Conclusions: Gasoline fumes showed to have adverse effects on pulmonary functions of car maintenance workers at gas stations especially in lower airways with restrictive type of pulmonary disease. In order to prevent lung damage in car maintenance workers at gas stations, awareness programs should be conducted and periodic medical pulmonary function tests checkups should be conducted to detect any pulmonary function impairment at the earliest.

Keywords: vehicle exhaust, air pollution, pulmonary function test (PFT), respiratory symptoms
Volume 2 Issue 3 - 2015

\author{
Rami Alyami, Jamal Alomar, Abdurhman \\ Alobireed, Mohammed AlAhmari \\ Jazan University, Prince Sultan Military College of Health \\ Sciences, Dammam University, Saudi Arabia
}

Correspondence: Rami Alyami, Jazan University, Saudi Arabia, Email rt.rami@hotmail.com

Received: February 25, 20I5 | Published: April 0I, 2015

\section{Introduction}

Air pollution from vehicles is an inevitable part of the workers at gasoline stations. A long-term exposure to vehicles exhaust leads to damaging effects on the respiratory function. ${ }^{1}$ The present study aimed to investigate the extent of lung function changes due to exposure to exhaust vehicles on car maintenance workers at gas stations. We also assessed the effect of the duration of the service at the gas stations on lung function decline.

\section{Settings}

Gas stations in Dammam, Eastern Province, Saudi Arabia

\section{Methods}

Twenty males aged from 18-40years whom working in gas stations as a cars mechanics were recruited in this study (Table 1). They were categorized into two groups, depending on the duration of the exposure [first group $>5$-years; second group $<5$ years]. Lung function parameters were measured as FEV1, FVC, FEV\% and FEF1 (25-75), using portable spirometry during their working hours. For air pollution, MIRAN Sapphire Portable Ambient Analyzer, Gray Wolf and Aerosol and Dust Monitors were used and its value was compared with World Health Organization (WHO) and Saudi standards. Data were analyzed using Graph Pad Prism 5 software (Graph Pad Software Inc., La Jolla, CA, USA). The Kolmogorov-Smirnov test of normality was applied. Descriptive analysis was applied. A one-way ANOVA was run to examine differences between the groups, followed by post hoc Bonferroni multiple comparison tests. A p-value 0.05 was considered statistically significant. 
Table I Demographic information of gasoline workers enrolled in this study

\begin{tabular}{lll}
\hline Subjects $\mathbf{n}=\mathbf{2 0}$ & Mean & SD \\
\hline Gender male \% & 100 & \\
Age $(\mathrm{yrs})$ & 25.9 & 5.90 \\
Weight $(\mathrm{kg})$ & 79.6 & 12.79 \\
Height $(\mathrm{cm})$ & 169.7 & 4.50 \\
Length of service at gasoline station $(\mathrm{yrs})$ & 4.22 & 3.62 \\
Days of Work per week & 7 & 0 \\
Hours of Work per day & 14.25 & 1.33 \\
\hline
\end{tabular}

\section{Results}

The most prevalent symptoms of workers were shortness of breath, dizziness and chest pain. Workers with less than 5years showed symptoms as follow: $10 \%, 30 \%$ and $25 \%$; while the workers with more than 5years: $30 \%, 35 \%$ and $30 \%$ (Figure 1).

FVC (L) and FEV1 (L) data showed significant decrease compared to the control group [ANOVA $\mathrm{p}=0.006$; ANOVA $\mathrm{p}=0.007$ ], while $\mathrm{FEV} 1 / \mathrm{FVC} \%$ value showed significant increase compared to the control group [ANOVA $\mathrm{p}=0.001$ ] (Figure 2).

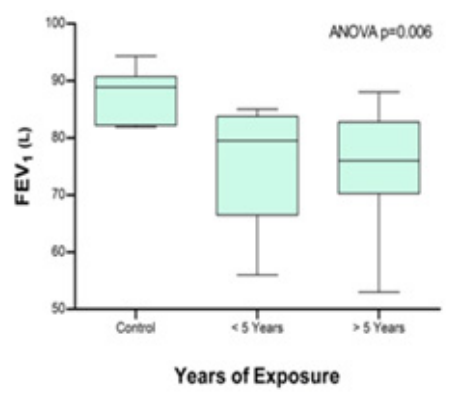

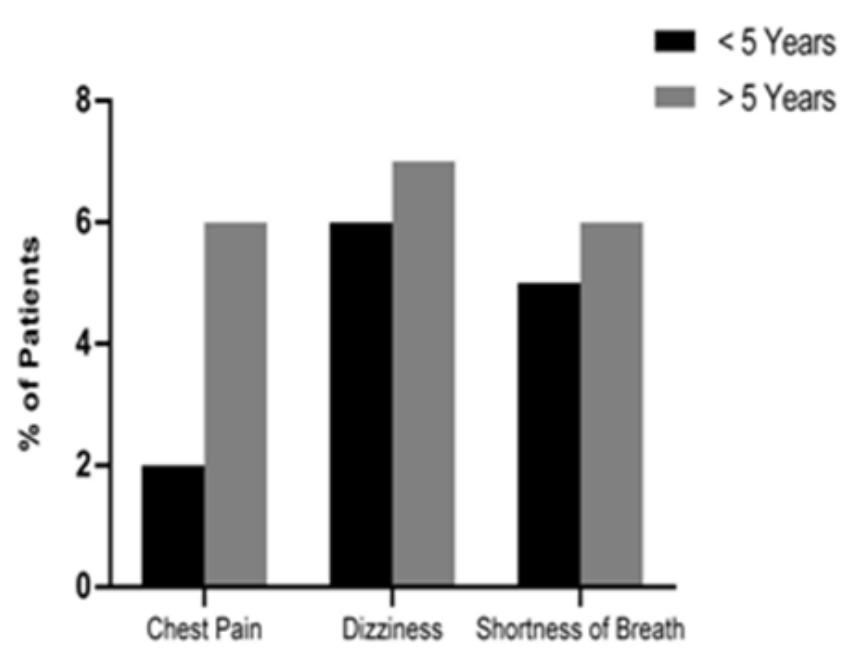

Figure I Comparison for the respiratory symptoms between the gas stations workers depending on the duration.

Air pollution data showed a significant increase in dust, $\mathrm{NO}_{2}, \mathrm{VOC}$ and $\mathrm{SO}_{2}$ comparing with $\mathrm{WHO}$ and Saudi Standards, as illustrated in Figure 3A, Figure 3B.
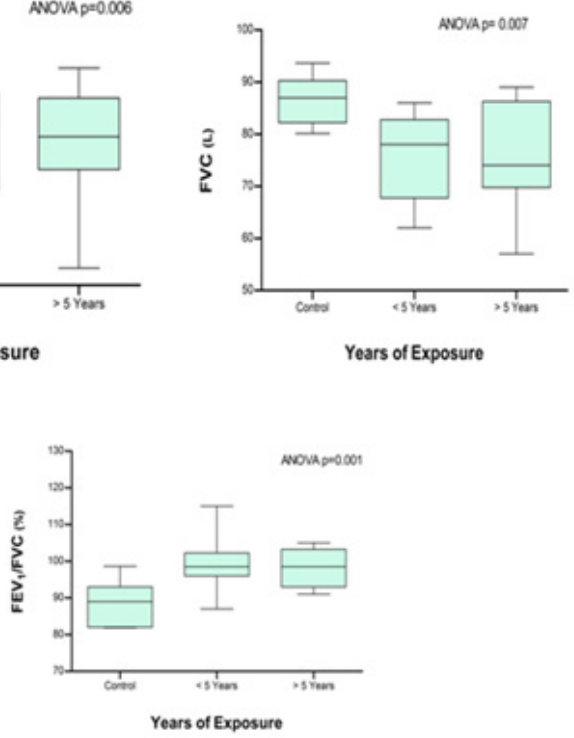

Figure 2 Mean value of lung function tests in gas stations workers according to duration of exposure. Significant differences illustrated using ANOVA with post hoc analysis. Lines represent mean \pm SD.
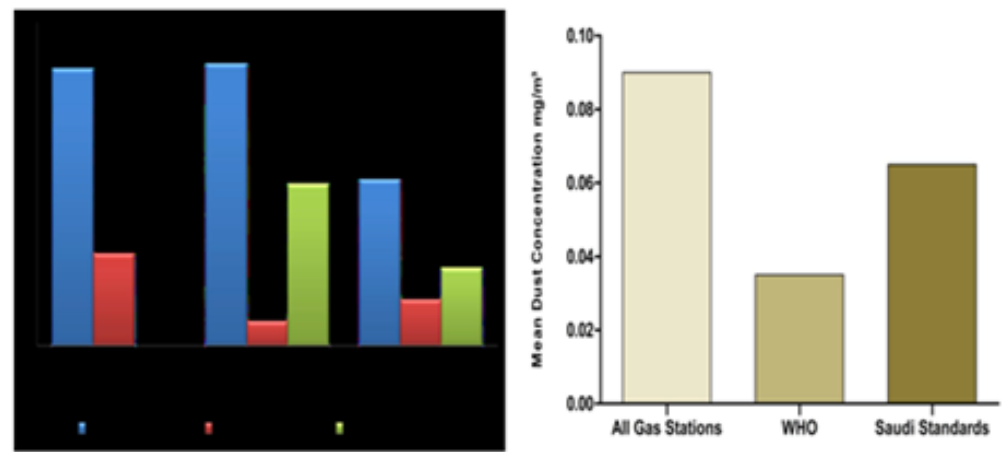

Figure 3

A. Mean of VOC, $\mathrm{NO}_{2}$ and $\mathrm{SO}_{2}$

B. Mean of Dust concentrations in different gas stations in comparison with WHO and Saudi. 


\section{Conclusion}

The above findings point towards adverse effects of gasoline fumes on lung functions, mainly on lower airways with restrictive pattern of disease.

\section{Acknowledgements}

None.

\section{Conflict of interest}

The author declares no conflict of interest.

\section{References}

1. Singhal M, Khaliq F, Singhal S, Tandon OP. Pulmonary functions in petrol pump workers: a preliminary study. Indian J Physiol Pharmacol. 2007;51(3):244-248. 